\title{
STEM Learning: Foundations
}

\author{
Eileen Scanlon, Christothea Herodotou, \\ Denise Whitelock and Chris Edwards
}

The first joint project undertaken by the Computers and Learning research group was the evaluation of The Open University Science Faculty's CAL offering in 1979. Since then many CALRG activities such as PhD projects, major external research grants, and institutional contributions, have been directed towards a better understanding of what makes science teaching and learning better. In this chapter we will consider our work on conceptual change in science and on the development of pedagogy and technology on personal inquiry using nQuire, and include work integrating these developments into the Open Science Laboratory. Our work has included evaluation of other innovative pedagogical supports such as the PuckLand simulation for teaching Physics, Virtual Field Trips and the use of the Virtual Microscope both in the UK and a number of other UK and EU universities. We illustrate how judicious use of technology and pedagogy can promote enthusiastic engagement with science and give opportunities for participation and learning.

\section{Introduction}

At The Open University's (OU) inception there were those who doubted that science can be taught at degree level to students accepted on an 'open entry'

How to cite this book chapter:

Scanlon, E., Herodotou, C., Whitelock, D. and Edwards, C. 2019. STEM Learning:

Foundations. In: Ferguson, R., Jones, A. and Scanlon, E. (eds). Educational Visions: Lessons from 40 years of innovation. Pp. 127-138. London: Ubiquity Press. DOI: https://doi.org/10.5334/bcg.h. License: CC-BY 4.0 
basis, i.e. without prior entrance qualifications. The OU developed science degrees from its first inception and the number of students registered with the university to start science degrees in the 1990s had reached ten percent of all the full-time science students in the UK (Pentz, 1978). These initial attempts were watched closely as there was some scepticism from the Higher Education establishment of the time that this could be done.

Since the first attempts at teaching science in the OU fifty years ago, the successful learning experiences designed for Open University science students have demonstrated that so much is possible. The change in perceptions about the feasibility of learning and teaching science at a distance is in part due to the developments in the technologies available to support appropriate activities. The courses were designed to help students learning on their own so that every activity was designed carefully, following pedagogical principles, and tested before it was sent to students. This was important because OU students did not have a lecturer to explain things to them if anything was not clear. However, experiments could be refined and revised for residential schools.

The importance of practical work in the teaching of science has always been an essential component of science teaching and emphasized in the literature (see e.g. Hofstein, 2007; Holstermann et al. 2010.) Practical work was dealt with by the incorporation of a variety of media in courses; including home experiment kits, radio or audiotapes, TV and laboratory classes at day schools as documented in Ross and Scanlon, 1995. Technology enhanced learning techniques and tools became more available and these were appropriate to help with this task too.

Why is science hard to learn? There are particular challenges for teaching and learning science at a distance. The OU's system offered the opportunity to study science to those with no previous qualifications in the subject. These ranged from the lack of prerequisites for study, the hierarchical nature of concepts needed to build science content knowledge, the need to develop mathematical skills, and develop practical work (Ross and Scanlon, 1995).

Technology was deployed very early in the development of a pedagogy of teaching science at a distance at the OU. This included the introduction of technology to the mix of media adopted in the first years of the university. A media mix that was heavily text based included also broadcast TV, audio and from the mid-1970s the use of computers. In the late 1970s an evaluation of early attempts at the use of CAL in the science faculty reviewed remedial CAL tutorials delivered on terminals available (for limited access) at study centres and simulation programmes available at residential or day schools (see Scanlon et al. 1987, Jones et al. 1982. 1987a,1987b). In our first case study we consider the use of simulation and modelling arising from these first years' experiences.

\section{Case Study one: Simulations and modelling}

Early experiments with the use of computers in teaching science involved simulations and modelling. In a simulation the process or system is modelled and then made available to the user so that, by playing with the system, they can get some insight into what is being modelled. So, experiments can be simulated 
that would be impossible to interact with in real life for reasons of access, expense time constraints or other considerations. A number of publications trace this work (e.g. Every and Scanlon, 1983; Ross and Scanlon, 1995, Blake \& Scanlon, 1996, 2007).

One issue which emerged from the evaluation of our CAL simulations (Jones, Scanlon, and O'Shea, 1987) was the importance of prior knowledge of the concepts which is often assumed in the design of the simulations. Sustained work on science learning in the past 40 years explored how science conceptions are developed. One example of our work on science concepts was the project, funded by the Economic and Social Research Council on using simulations for the development of conceptual change ( the ESRC-funded 'Conceptual Change in Science' project). Our aim was to promote change in learners' understanding of physical phenomena. This work included the design and development of a set of teaching materials for the teaching of a topic on mechanics. These teaching materials included interactive computer simulations of force and motion, along with practical activities and written materials. The method involved making learners aware of the limitations of their current conceptions of force and motion. Then, learners would be helped to develop and use a conceptual framework which conformed to current scientific understanding. This would have to be in line with their experience and be internally consistent. Conceptual change was found to be developed in this sequence of lessons. The children on whom the curriculum was tested displayed more sophisticated reasoning than their counterparts in comparison classes (Hennessy et al. 1995a, 1995b). This work influenced the development of simulations used in distance education settings. One particular finding, that the conceptual change in science software was most effective in situations where practical experimental work was combined with work with simulations, was particularly important, see Twigger et al., 1994. (Another example of the influence of this work on the design of teaching, was the Supported Learning in Physics Project (SLIPP), where we used OU expertise in support of teacher education in schools Whitelegg and Edwards, 2001.)

An extension of the simulation which consists of a mathematical model of some process underlying the system is that of a virtual environment. Laurillard (2001 p 36) points out 'virtual environments use a graphical model to display the visual and positional properties of the system rather than its behaviour'. The examples of virtual field trips and virtual microscope are discussed below.

Another connected strand of work involved a number of $\mathrm{PhD}$ theses on modelling physics problem solving, and graphical representations (link to CALRG theses lists in the library). These projects looked in detail at students' current conceptions of different science topics and made use of detailed protocol analysis of users' interactions with computer systems as they solved problems to produce rich pictures (thick descriptions of students talking, writing and interacting with technology) to help us understand what ideas and interactions were causing difficulties with instruction (see also Driver and Scanlon, 1988).

One particular problem that Physics students encounter is that of understanding elastic collisions. A simulation known as PuckLand was developed 
which allowed students to investigate the interaction between two ice pucks. This early work was written in HyperCard for use with the Apple Macintosh and consisted of a pair of pinball-style flippers on either side of the screen with which subjects could flick pucks (see Figure 8.1).

The amount of force with which the flippers hit the pucks could be varied by raising the height of the flippers as could the mass of the pucks. When the 'go' button was activated the pucks moved towards each other on the screen and were animated with speeds proportional to those set by button presses. After the pucks collided, they moved away from each other with a speed that was calculated with the correct Physics formalisms. In this way, the principle of conservation of momentum and kinetic energy were obeyed as illustrated by the apparent screen velocities of the pucks.

The empirical study undertaken with this simulation involved 16-17 year old Physics students working in pairs and this research was an early foray into computer supported collaborative learning. The initial findings revealed that students develop two families of causal models to explain motion after a collision. These have been identified as the linear causal and the resistance/ reciprocal causal model. However, these models broke down when the students were confronted with the animations from the PuckLand simulation.
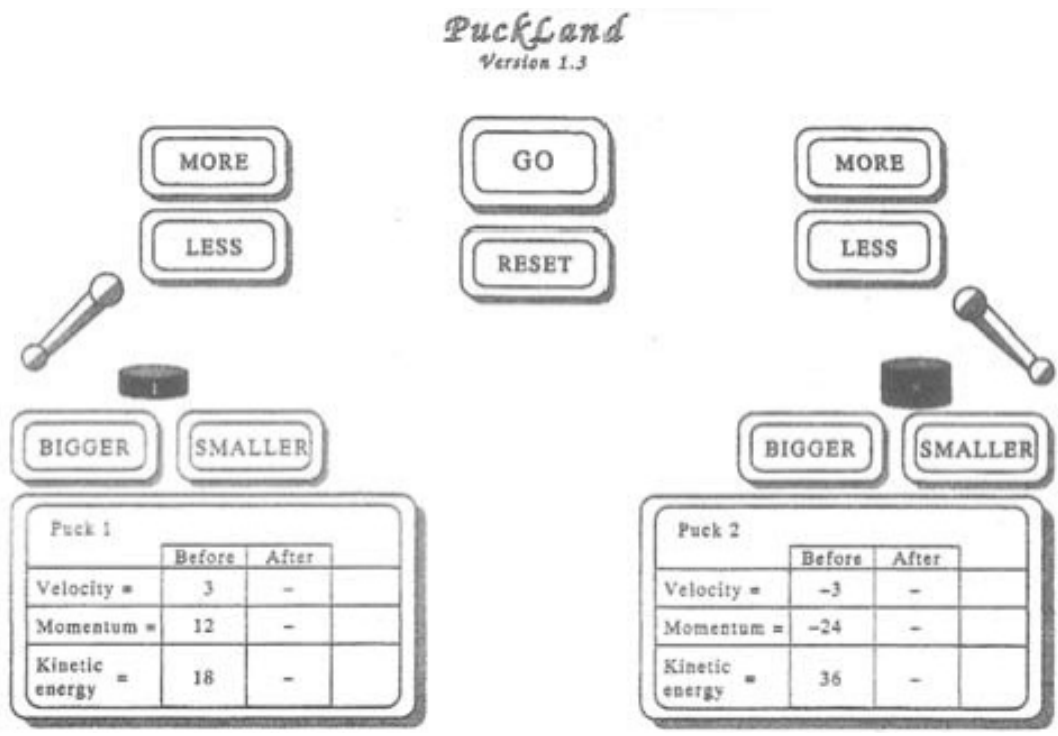

Figure 8.1: Screen dump of the graphic interface to the PuckLand program. Reprinted from Computers \& Education 20 (1). D. Whitelock, T. Taylor, T. O'Shea, E. Scanlon, R. Sellman, P. Clark, C. O'Malley, Challenging models of elastic collisions with a computer simulation, pp. 1-9, copyright Pergamon Press Ltd (1993), with permission from Elsevier. 
The result being that the students were moved to rethink their commonsense ideas about motion which lacked an understanding of conservation of energy.

A second study involved pairing the students with either "similar" or "different" common-sense models of collisions. It is interesting to note this early work suggested that the cooperative construction of shared meaning rather than conflict was more important for successful collaboration (Barbieri \& Light, 1993). It is interesting to note that the PuckLand simulation, although routed in Science teaching and learning, was also able to prompt further investigation into computer supported collaborative learning and to provide a further vignette into the practical application of social constructivist theory.

\section{Case study 2: Practical work-home kits, residential schools and multimedia approaches}

In an earlier Chapter (4) Coughlan et al. describe an approach to one particular problem of learning science at a distance, that of access to practical experiences. They describe one particular solution in the work researching remote laboratories (see also Scanlon et al., 2004). However, this was only one approach taken to the knotty problem of providing practical experiences for online distance learning of science. Initially the means of making practical experiences available to students was the provision of extensive home experiment kits, residential schools and broadcast TV programmes.

More recently the provision of multimedia meant that students can have vicarious experience of observing experiments. In addition there is the possibility of controlling variables and drawing inferences. An introductory science course offered at The Open University in the 1990s offered students the possibility of interacting with a global warming simulation, taking a virtual desert field trip and conducting Galapagos field trips (see e.g. Taylor et al. 1996; Whitelock, 2001) sometimes with a problem-solving pedagogy applied (see e.g. Ross and Bolton, 1990). Virtual field trips where users explore a threedimensional environment have been used (see e.g. Whitelock, 2001; Whitelock and Jelfs, 2005).

Furthermore, Whitelock with co-authors Brna and Holland (1996), selected three properties of virtual environments to incorporate into a model that could compare salient properties of virtual systems that would be open to test. These properties included representational fidelity, immediacy of control and presence which could define a finite but still a large space of VE classes. This model was used to understand the factors in virtual environments that promote conceptual learning by comparing two desktop virtual environments which explored field trips to the North Atlantic Ridge by submarine and a walk through an oak wood (Whitelock, 1999). The representational fidelity was rated higher for the oak wood than the North Atlantic Ridge. Immediacy of control was perceived differently in the two VR programs due to the jerky movements experienced in these early desktop VR environments. However, the role of audio was found to be important in more than one way when virtual environments are being 
built for conceptual learning. this is because they create a sense of presence, engagement and enjoyment but are also important for navigation. The latter is not such a trivial point as first may appear since the cognitive load could be diminished if navigation was easier and students could concentrate on understanding and manipulating concepts within the subject domain. It is interesting to note that virtual reality systems still require navigational and conceptual compasses for conceptual learning as suggested from this 1999 study. Of a similar vintage is our original Virtual Microscope project which simulates the views through a microscope of slides displaying different kinds of materials Whalley et al., 2011. This has particular benefits for students with accessibility issues as described in Chapter 4. For example, it provides access for students with difficulty in reaching laboratories and better access to images for students who are partially sighted.

\section{Case study 3: Personal Inquiry project}

A significant advancement in the available technologies to support the development of science understanding had the effect of sparking a new extended investigation into how technologies can enable science learning in contemporary contexts. In the context of a 'Personal Inquiry' (PI) project funded by the ESRC and Engineering \& Physical Sciences Research Council (EPSRC), we explored the conditions under which evidence-based inquiry learning can be fostered. The PI project aimed to understand how personal and mobile technologies can be deployed to make the processes of evidence-based scientific inquiry readily accessible to young people (see Anastopoulou et al., 2008, 2012). As Blumenfeld et al. (1991) point out, technology has a potentially useful role to play in structuring the process of inquiry learning with tactical and strategic support.

Making scientific inquiry authentic is a challenge that has been discussed by a number of researchers (e.g. Edelson et al., 1999; Chinn and Malhotra, 2002). A personal inquiry toolkit was developed to scaffold this activity and was tried out in a number of school-based interventions, two in Nottingham schools and two in Milton Keynes. The young people carried out scientific explorations supported by their teachers and also by a personal inquiry toolkit. This toolkit, in its first instantiation, ran on a small portable computer and guided the learners through a process of gathering and assessing evidence, whilst they conducted experiments on topic themes of relevance to the secondary-level UK National Curriculum. Further technology support was provided by data probes connected to the computer. Project partners included schools, technology companies that develop sensing and data-logging equipment, museums, community resource centres and field trip sites. This broad partnership reflected our view that we need to support learning within the classroom and outside it whether on field trips or at home.

At the culmination of this project we developed nQuire, a software application to guide personal inquiry learning. nQuire provides teacher support for 
authoring, orchestrating and monitoring inquiries as well as student support for carrying out, configuring and reviewing inquiries. nQuire allows inquiries to be scripted and configured in various ways, so that personally relevant, rather than off-the-shelf inquiries, can be created and used by teachers and students. nQuire incorporates an approach to specifying learning flow that provides flexible access to current inquiry activities without precluding access to other activities for review and orientation. Dependencies between activities are automatically handled, ensuring decisions made by the student or teacher are propagated through the inquiry. nQuire can be used to support inquiry activities across individual, group and whole-class levels at different parts of the inquiry. It offers a flexible, web-based approach that can incorporate different devices (smartphone, netbook, PC) and does not rely on constant connectivity (Mullholland et al., 2011). We published a set of studies of orchestration of inquiry within and beyond the classroom (Sharples, 2013; Sharples et al., 2015) and illustrated how the inquiry framework and nQuire toolkit together influenced the performance and effectiveness of inquiry learning (Littleton et al., 2013). This paradigm has been further developed to scaffold online personal inquiry learning within informal settings. For example the nQuire platform has also been used in Higher Education in The Open University's Open Science Lab (see Theme 2) to support informal examples of inquiry learning (Villasclaras Fernandez et al., 2013).

\section{Case Study 4: The iSpot Project}

The aim of iSpot (www.ispotnature.org) (see Figure 8.2) is to create a new generation of naturalists by helping students and people of all ages learn how to identify organisms by enhancing natural history identification skills. It was launched in 2009 and developed initially with a five-year, $£ 2$ million grant from the Big Lottery Fund for England. This skill (to identify likely IDs for observed flora and fauna) underlies all of biodiversity science. However, this is no longer widely taught in formal curricula in schools or universities. A South African site followed (www.ispot.org.za) and in 2013 a version for Chile was also created (www.ispotnature.org/chile). iSpot has 65,000 registered users who have made more than 550,000 observations of many thousands of species.

In working with the development of iSpot we have contributed to learning but also to scientific discoveries through observations communicated on the platform. The observations included two which had not been recorded in the UK before. A six-year-old girl discovered a moth on her windowsill. The moth, native to Asia, had never before been spotted in the UK. After identification on iSpot, the species was also confirmed by experts and the moth was taken into the Natural History Museum collection. In addition, in South Africa, a doctor submitted a photograph of unknown seeds that were the cause of poisoning in several children presenting at a clinic and these were identified 35 seconds after posting on iSpot (iSpot 2013). Hitherto unknown populations of South African endemic plant species are regularly discovered on iSpot (Silvertown et al., 2015, p. 142). 


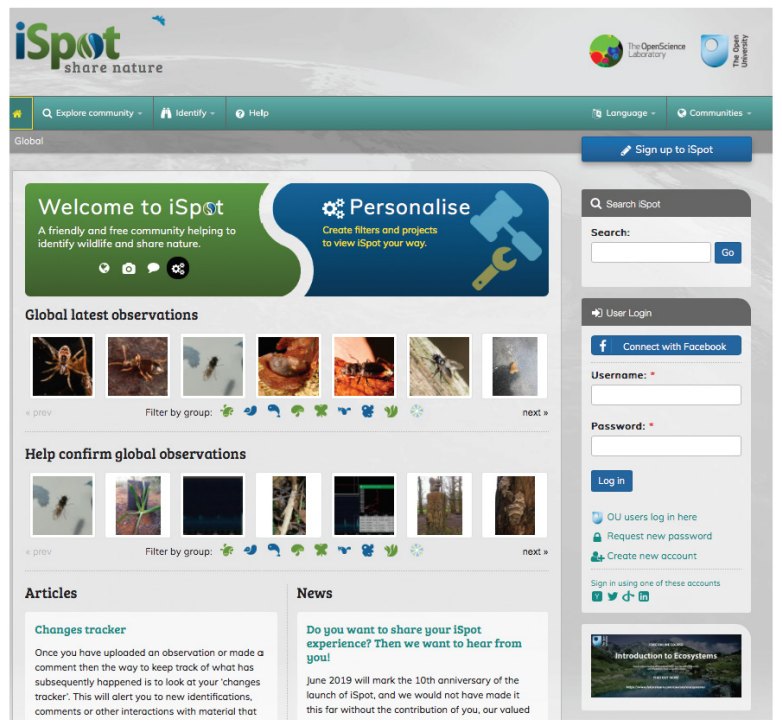

Figure 8.2: The iSpot platform supporting species identification.

iSpot was incorporated into the OU's Open Science Laboratory which allows anyone, anywhere to access practical science education. iSpot also supports Open University / BBC broadcasts, the Open Science Laboratory, and was used in three environmental courses.

We were involved in the design, development and running of the platform and the evaluation of learning on the platform (Scanlon et al., 2014). iSpot provides an online community where novices and experts can work together to identify living organisms and engage in crowdsourcing identification. iSpot allows anyone, anywhere, to upload an image for identification in towns, back gardens, open fields, forests and all sorts of habitats across the country. This contributes to solving the problem of learning about nature. Also, the information gathered by iSpot is used for other data collection for conservation purposes.

The impact of iSpot on learning has been measured in a couple of ways. Learning episodes are short and informal. So, we needed to think about the impact of iSpot and the potential outcomes, including increased awareness and impact on attitudes, as well as engagement and participation. It is complex to examine such learning settings as iSpot. Qualitative analysis does show clear examples of users who start as complete novices, and then come to a good understanding of identification. There is also some quantitative evidence of users learning. For instance, analysis of a sample of 407 users as they progressed through submitting and identifying their first 50 observations within iSpot is strongly suggestive of learning as users showed improvement in their ability to identify other people's observations over the period that they submitted observations: 
As users progress from their first to their 50th observation posted on iSpot they have a bigger percentage of correct identifications, that is they are more likely to identify what they have seen for themselves. This change in behaviour probably reflects learning, although other causes of the trend may be possible (Silvertown et al., 2015).

\section{Conclusions}

A range of science-related projects have been undertaken over the last 40 years (see also the account in Scanlon 2011) which aims to support learners to learn science from a distance, and without previous academic qualifications, and to build connections between formal and informal learning in order to foster their interest and curiosity in science. Major milestones in the journey of engaging learners with science have been the development of science simulations and modelling and their support of conceptual change (Case Study 1), technology mediated practical work, (Case Study 2), the Personal Inquiry (PI) project that scaffolded the process of scientific inquiry through technology (Case Study 3), and iSpot that leveraged the power of the crowd to support species identification (Case Study 4). This journey aimed to bring science closer to the everyday life of learners and help them understand and appreciate its value by developing bridges between formal and informal education. It also aimed to open up and make science accessible thus enabling potentially anyone to engage with science activities. These technological developments promote enthusiastic engagement with science and give opportunities for participation and learning. For example, the use of simulations allows for hands-on experimental work to take place at any time, in a playful manner and by learning through failure, exploration and experimentation. Simulations lower the barriers to participation and make it easy for people to engage with activities often viewed as determined by scientists. In relation to our Beyond Prototypes themes (see Chapter one) this chapter illustrates the effect of the 'persistent intent' of a succession of teachers and researchers who were determined to meet our initial challenge from many commentators that as far as science learning at a distance goes, 'It can't be done'.

The above line of work suggests that certain aspects can support the process of engagement with science including an understanding of what people need to know in order to effectively do science, both in formal and informal settings, such as knowledge of basic science-related concepts, and relevant mathematical skills and skills for practical work. Also, an explicit account of hard to grasp concepts should be developed through studies with online learners, in order to identify and improve issues they are struggling with. Such an account could inform the design of more effective science learning experiences that consider the challenges or demands of self-regulated learning, such as the significance of appropriate scaffolding when learners complete tasks on their own. 


\section{References}

Anastopoulou, S., Sharples, M., Ainsworth, S., Crook, C., O’Malley, C., \& Wright, M. (2012). Creating personal meaning through technology-supported science inquiry learning across formal and informal settings. International Journal of Science Education, 34(2), 251-273.

Anastopoulou, S., Sharples, M., Wright, M., Martin, H., Ainsworth, S., Benford, S., O'Malley, C. (2008). Learning 21st century science in context with mobile technologies. In J. Traxler, B. Riordan, \& C. Dennett (Eds.), Proceedings of the mLearn 2008 conference: The bridge from text to context (pp. 296-303). Wolverhampton, England: University of Wolverhampton.

Barbieri M. and Light, P. (1993). Interaction, gender and performance on a Computer Based Problem Solving Task. International Journal of Educational Research.

Blake, C. and Scanlon, E. (2007). Reconsidering simulations in science education at a distance: features of effective use. Journal of Computer Assisted Learning, 23(6) pp. 491-502.

Blake, C., Butcher, P., Scanlon, E. and Jones, A. (1996). The Works Metallurgist: an evaluation of a CAL package on phase diagrams. ALT-J: Research in Learning Technology, 4(1) pp. 55-57.

Blumenfeld PC, Soloway E, Marx RW, Krajcik JS, Guzdial M, Palincsar A (1991). Motivating project-based learning: sustaining the doing, supporting the learning. Educ Psychol 26(3-4):369-398.

Chinn, C. and Malhotra, B. (2002). Epistemologically Authentic Inquiry in Schools: A Theoretical Framework for Evaluating Inquiry Tasks Science Education, Vol 86, No 2.

Driver, R., Scanlon, E. (1988). Conceptual change in science: A research programme, Journal of Computer Assisted Learning, Vol. 5, Issue 1.

Edelson, D.C, Gordin, R.D. and Pea, R.D. (1999). Addressing the challenges of inquiry-based learning through technology and curriculum design, Journal of the Learning Sciences 8 (3-4), 391-450.

Every, I. and Scanlon, E. (1983). Discovering physics with microcomputers. Computers and Education, 8(1) pp. 183-188.

Hennessy, S., Twigger, D., Byard, M., Driver, R., Draper, S., Hartley, J. R., Mohamed, R., O’Malley, C., O'Shea, T., and Scanlon, E. (1995a). Design of a computer-augmented curriculum for mechanics. International Journal of Science Education, 17 (1), 75-92.

Hennessy, S., Twigger, D., Byard, M., Driver, R., Draper, S., Hartley, J. R., Mohamed, R., O'Malley, C., O'Shea, T., and Scanlon, E. (1995b). A classroom intervention using a computer-augmented curriculum for mechanics. International Journal of Science Education, 17(2) 189-206.

Hofstein, A. and Mamlok-Namman, R. (2007). The laboratory in science education: the state of the art. Chemistry Education Research and Practice 8, 105-107. 
Holstermann, N., Grube, D. and Bögeholz, S. (2010). Hands-on activities and their influence on students' interest. Research in Science Education 40, 743-757. Jones, A., Scanlon, E. and O〉Shea, T. eds. (1987a). The Computer Revolution: New Technologies for Distance Teaching. Brighton: Harvester Press.

Jones, A., O'Shea, T. and Scanlon, E. (1987b). Evaluation of Computer Assisted Learning at The Open University. In Jones, A., Scanlon, E. and O'Shea, T. (eds) The Computer Revolution in Education. Harvester Press, ISBN 0-71080985-9, pp263-276.

Jones, A., and O'Shea, T. (1982). Barriers to the use of computer assisted British Journal of Educational Technology, Vol 13,No 3.

Laurillard, D. (2001). Rethinking University Teaching, Routledge Press.

Littleton, K., Scanlon, E. and Sharples, M. (2012). Orchestrating Inquiry Routledge Press.

Mulholland, P., Anastopoulou, S., Collins, T., Feisst, M., Gaved, M., Kerawalla, L., Paxton, M., Scanlon, E., Sharples, M. and Wright, M. (2011). nQuire: Technological support for personal inquiry learning. IEEE Transactions on Learning Technologies. First published online, 5th December 2011. 5(2) pp. 157-169 http://doi.ieeecomputersociety.org/10.1109/TLT.2011.32

Pentz, M. (1978). 'It can't be done' Lecture at Royal Institution.

Ross, S. and Scanlon, E. (1995). Technology and Pedagogy. In Open Science; the distance teaching and open learning of science subjects, London: Paul Chapman Publishing.

Ross, S. and Bolton, J. (2002). Physica: a computer environment for Physics problem-solving. Interactive Learning Environments, 10(2) pp. 157-175.

Scanlon, E. (2011). Technology-enhanced science learning at a distance, Open Learning:The Journal of Open and Distance Learning, 24 (2).

Scanlon, E. How novices solve physics problems. pp176-186 In Jones, A., Scanlon, E. and O'Shea, T. (eds) The Computer Revolution in Education. Harvester Press, 1987.ISBN 0-7108-0985-9

Scanlon, E., Woods, W., \& Clow, D. (2014). Informal Participation in Science in the UK: Identification, Location and Mobility with iSpot. Educational Technology \& Society, 17 (2), 58-71.

Scanlon, E., Jones, A. and O’Shea, T. (1982). Evaluating CAL at The Open University, In The Computer Revolution in Education, Lewes, UK: Harvester Press.

Scanlon, E., Sharples, M., Fenton-O’Creevy, M., Fleck, J., Cooban, C., Ferguson, R., Cross, S. and Waterhouse, P. (2013). Beyond prototypes: Enabling innovation in technology-enhanced learning. Open University, Milton Keynes.

Scanlon, E., Colwell, C., Cooper, M., and Di Paolo, T. (2004). Remote experiments, re-versioning and re-thinking science learning. Computers \& Education, 43(1-2) pp. 153-163.

Scanlon, E. (2011). Technology enhanced learning in science: interactions, affordances and design-based research. Journal of Interactive Media in Education, 24 (2). 
Sharples, M. (2013). Shared orchestration within and beyond the classroom. Computers and Education, 69 pp. 504-506.

Sharples, M., Scanlon, E., Ainsworth, S., Anastopoulou, S., Collins, T., Crook, C., Jones, A., Kerawalla, L., Littleton, K., Mulholland, P. and O’Malley, C. (2015). Personal inquiry: orchestrating science investigations within and beyond the classroom. Journal of the Learning Sciences, 24(2) pp. 308-341.

Silvertown, J., Harvey, M., Greenwood, R., Dodd, M., Rosewell, J., Rebelo, T., Ansine, J. and McConway, K. (2015). Crowdsourcing the identification of organisms: a case-study of iSpot. ZooKeys, 480 pp. 125-146.

Taylor, J., Scanlon, E. and Hodgson, B. (1996). Multimedia and Science Education, Education Research and Perspectives, 23 (2), 48-58.

Twigger, D., Byard, M., Driver, R., Draper, S., Hartley, J. R., Hennessy, S., Mohamed, R., O'Malley, C., O'Shea, T., and Scanlon, E. (1994). The conceptions of force and motion of students aged between 10 and 15 years: an interview study designed to guide instruction. International Journal of Science Education, 16 (2), 215-229.

Villasclaras Fernandez, E., Sharples, M., Kelley, S. and Scanlon, E. (2013). Supporting citizen inquiry: an investigation of Moon rock. In: Scaling up Learning for Sustained Impact, Lecture Notes in Computer Science, Springer, pp. 383-395.

Whalley, P., Kelley, S. and Tindle, A. (2011). The role of the Virtual Microscope in distance learning. Open Learning: The Journal of Open and Distance Learning, 26(2) pp. 127-134.

Whitelegg, E. and Edwards, C. (2001). Beyond the laboratory: learning physics in real-life contexts. In: Behrendt, Helga; Dahncke, Helmut; Duit, Reinders; Graber, Wolfgang; Komorek, Michael; Kross, Angela and Reiska, Priit eds. Research in science education: past, present and future. Dordrect, Netherlands: Kluwer Academic Publishers, pp. 337-342

Whitelock, D., Taylor, J., O’Shea, T., Scanlon, E., Clark, P. and O’Malley, C. (1993). 'Challenging Models of Elastic Collisions with a Computer Simulation.' Journal of Computers in Education. Vol 20, No. 1 pp 1-9. Pergamon Press.

Whitelock, D.M., Brna., P. and Holland, S. (1996). What is the value of virtual reality for conceptual learning? Towards a theoretical framework. In: P. Brna, A. Paiva and J.A. Self (eds) Proceedings of the European Conference on Artificial Intelligence in Education, Lisbon, 127-132.

Whitelock, D. (1999). Investigating the role of task structure and interface support in two virtual learning environments. International Journal of Continuing Engineering Education and Life-Long Learning, 9(3/4) pp. 291-301.

Whitelock, D. (2001). Going Live to the Galapagos Islands and an Oak Wood: S103 Student Responses to some Biological Multimedia Programs IET internal report Program on Learner Use of Media report No 138.

Whitelock, D. and Jelfs, A. (2005). 'Would you rather collect data in the rain or attend a virtual field trip?': Findings from a series of virtual science field studies. International Journal of Continuing Engineering Education and LifeLong Learning, 15(1-2), pp. 121-131. 